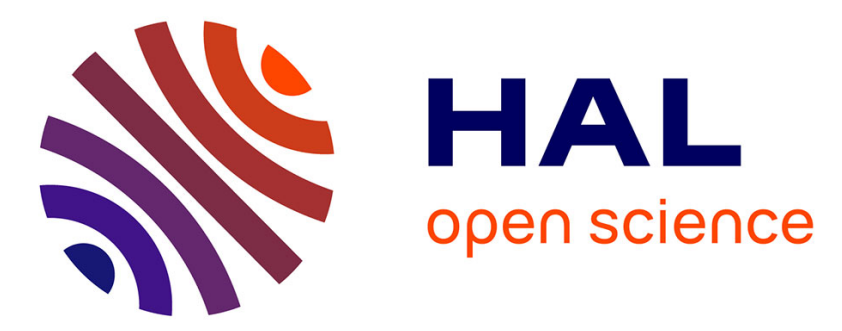

\title{
Influence of mean stress and mean strain on fatigue life of carbon black filled natural rubber
}

Elisabeth Ostoja-Kuczynski, Pierre Charrier, Erwan Verron, Laurent Gornet, Gilles Marckmann

\section{- To cite this version:}

Elisabeth Ostoja-Kuczynski, Pierre Charrier, Erwan Verron, Laurent Gornet, Gilles Marckmann. Influence of mean stress and mean strain on fatigue life of carbon black filled natural rubber. Fourth European Conference on Constitutive Models for Rubber (ECCMR 2005), Jun 2005, Stockholm, Sweden. pp.15-22. hal-01377483

\section{HAL Id: hal-01377483 \\ https://hal.science/hal-01377483}

Submitted on 7 Oct 2016

HAL is a multi-disciplinary open access archive for the deposit and dissemination of scientific research documents, whether they are published or not. The documents may come from teaching and research institutions in France or abroad, or from public or private research centers.
L'archive ouverte pluridisciplinaire HAL, est destinée au dépôt et à la diffusion de documents scientifiques de niveau recherche, publiés ou non, émanant des établissements d'enseignement et de recherche français ou étrangers, des laboratoires publics ou privés. 


\title{
Influence of mean stress and mean strain on fatigue life of carbon black filled natural rubber
}

\author{
E.Ostoja-Kuczynski \& P. Charrier \\ Modyn Trelleborg, Zone ind. de Carquefou, BP 419, 44474 Carquefou Cedex - France \\ E. Verron, L. Gornet \& G. Marckmann \\ Ecole Centrale de Nantes, Institut de Recherche en Génie Civil et Mécanique, BP 92101, 44321 Nantes cedex \\ 3, France
}

\begin{abstract}
The recent determination of end of life criteria for multiaxial loads enables to design new parts undergoing relaxing solicitations. The application of these criteria for non-relaxing solicitations, which represent more adequately the loads applied on antivibration parts on service, is still an unanswered matter. Previous studies carried out on test specimens highlight an increase on duration life when minimum solicitation is higher than a threshold level : this phenomenon is known as reinforcement. Parameters namely test control, load ratio and level of maximal solicitation were identified to be relevant to reinforcement phenomenon. In order to investigate their influence over duration life, an experimental campaign was performed. For each test condition, the mechanical threshold level where from which reinforcement appears is clearly identified. A single reinforcement law, suitable for propagation and initiation tests, is established.
\end{abstract}

\section{INTRODUCTION}

\subsection{Industrial context}

The design of antivibration parts taking into account durability is a critical challenge for automotive suppliers. Indeed, in the past, the component life validation was performed under sinusoidal loads only. Nowadays durability specifications imposed by carmakers are frequently real multiaxial loads that are directly measured on vehicles. These stochastic signals (cf. Fig. 1), named Road Load Data or RLD, may include a static pre-load (e.g. representative of engine weight) and need specific test rigs to reproduce then.

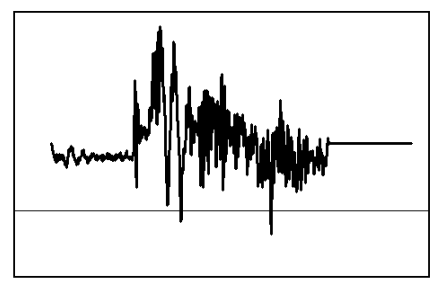

time

Figure 1 : Road Load Data example

The recent determination of end of life criteria for multiaxial loads enables the design of new parts undergoing relaxing solicitations, i.e. the fatigue load cycle minimum corresponds to the unloaded configuration. Extension of these criteria to nonrelaxing conditions (more representative of real applied loads) is still an unanswered problem.
The present work deals with mean stress corrections for locally uniaxial non-relaxing loads (i.e. equivalent to tensile test). This work is the first stage of a more global project which final target is the duration life prediction under multiaxial non-relaxing fatigue load conditions.

\subsection{Rubber fatigue characterization}

Previous works proposes two different approaches to characterize elastomer durability.

The first one, called crack initiation prediction, assumes that the test specimen is initially uncracked (Cadwell et al., 1940). The result of this approach is a Wöhler curve (durability versus local load amplitude) where the durability $\mathrm{N}_{\mathrm{i}}$ represents the number of cycles before occurrence of a predefined critical size crack. This leads to the general equation :

$N_{i}=A \cdot$ criterion $^{\alpha}$

where A and $\alpha$ are two parameters depending on the tested material and the load conditions, and criterion represents a measure of the applied mechanical load amplitude. Maximal principal strain or stress or elastic energy density are frequently used and discussed in most scientific papers.

The second one, called crack propagation prediction, is introduced by Thomas (1958) and resumes the initial work of Rivlin and Thomas on crack propagation under monotonic loads (Rivlin \& Thomas, 1953). Using a notched test specimen, the crack growth rate $\mathrm{dc} / \mathrm{dN}$ is measured as a function of 
dynamic applied tearing energy $\Delta \mathrm{T}$. The crack growth curve obtained is modeled by the following equation:

$\frac{d c}{d n}=B \cdot \Delta T^{\beta}$

where $\mathrm{B}$ et $\beta$ are two parameters depending on the tested material and the load conditions, and $\Delta \mathrm{T}$ is the effective tearing energy range (Charrier et al. 1998):

$$
\Delta T=T_{\max }-\max \left(T_{\min }, 0\right)
$$

\subsection{Initiation or propagation approach?}

From a classical theoretical point of view, fatigue failure should be dissociated in two phases : crack nucleation and crack propagation. For natural rubbers, the existence of these two separated steps is not yet proved. Only some recent publications propose experimental procedures to quantify the respective duration of each theoretical stage (Saintier 2001, Le Cam et al. 2004).

Though lacking concret understanding of the physical crack nucleation mechanisms in filled natural rubbers, most authors introduce a statistical distribution of pre-existing flaw in the rubber matrix. These authors assume that fatigue failure results only on the propagation of these internal preexisting flaws.

The mean-value size of this distribution is labeled $\mathrm{c}_{0}$ and is assumed to be characteristic of the material and the mixing / molding process. The experimental duration life enables to estimate $\mathrm{c}_{0}$ by inverse analysis. Result values obtained for $\mathrm{c}_{0}$ are generally contained between $20 \mu \mathrm{m}$ and $100 \mu \mathrm{m}$, which is in accordance with fractographic studies published by Piques \& Saintier (2001) and Le Cam et al. (2004).

Extension of this assumption to non-relaxing conditions appears to be from now on the chief challenge. Mars (2000) tried to predict Wöhler curves using crack growth properties measured under non-relaxing loads. However, an insufficient experimental database does not allow the author to conclude on this type of loading conditions.

The present study deals with the characterization of a filled natural rubber under relaxing and nonrelaxing loads using crack initiation and crack propagation approaches. Crack growth curves are then used to predict the measured Wöhler curves.

\section{EXPERIMENTAL RESULTS UNDER NON RELAXING CONDITIONS}

\subsection{Reinforcement phenomenon}

Several studies have been published concerning rubber durability under non-relaxing conditions. Both crack initiation (Cadwell et al. 1940, André et al. 1999) and crack propagation approaches (Lindley 1974, LeGorju \& Bathias 2002) have been studied. For all filled natural rubber, these works highlight a specific phenomenon named reinforcement. This phenomenon corresponds to the enhancement of the durability properties (decrease of crack growth rate or increase of duration life) when, keeping the maximum load condition constant, the minimum load condition becomes greater than a threshold. Such a loading condition is named reinforcing solicitation.

\subsection{Crack propagation test}

The test specimen for the present study consists of two notched parallelipedic rubber blocs (cf. Fig. 2). The entire test procedure used to measured the tearing energy $\mathrm{T}$ and the crack growth rate $\mathrm{dc} / \mathrm{dN}$ is fully described by Charrier et al. (2002).

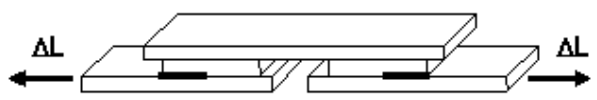

Figure 2 : Crack propagation test specimen under displacement control. The black bold line represents pre cracks.

Crack propagation law measured under relaxing conditions is classically modified under nonrelaxing condition. This phenomenon can be modeled by an evolution of $\beta$ (Lindley, 1974), or can affect the threshold $\mathrm{T}_{0}$ (LeGorju \& Bathias 2002). In the last case, the crack growth curve is only shifted.

Two crack growth curves characterizing the compound used in the present study are presented on Figure 3 . The first one corresponds to relaxing conditions and the second one is measured by enforcing a displacement ratio equal to 0.25 . These two curves have the same slope $\beta_{0}$.

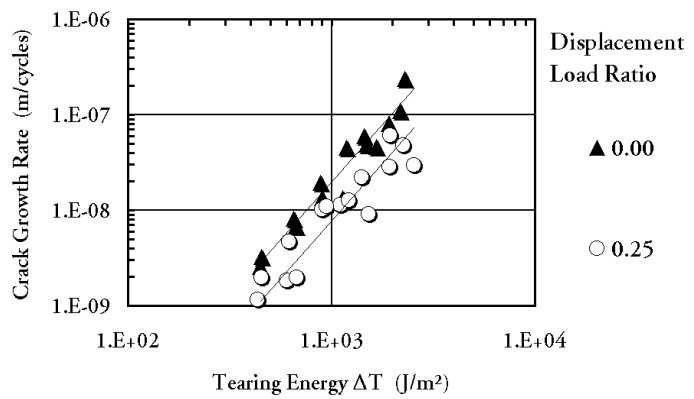

Figure 3 : Crack growth curve obtained under constant displacement load ratio

According to Figure 3, it is assumed that as far as the displacement ratio is lower than 0.25 and in the range of tested tearing energy, the value of $\beta$ is not modified under non relaxing conditions. Furthermore, this assumption may hold even for imposed force signals.

As a consequence, the general equation of the crack growth curve becomes : 


$$
\frac{d c}{d n}=f(R) \cdot B_{0} \cdot \Delta T^{\beta_{0}}
$$

where $B_{0}$ and $\beta_{0}$ are two parameters measured under relaxing condition, $\mathrm{R}$ is the load ratio (force or displacement) and $f(R)$ represents the shift of the crack growth curve induced by the reinforcement phenomenon. This also highlights the existence of a master curve driving the crack propagation rate.

Specific tests were performed to characterize the reinforcement threshold by fixing the maximum cyclic load level and variyng the minimum cyclic load level in order to study a large range of load ratio. Three maximum cyclic strain levels were considered: $125 \%, 187,5 \%$ and $250 \%$. Each resulting curve represents the crack growth rate evolution as a function of the load ratio (displacement ratio in Charrier et al. (2002) and force ratio in Fig. 4).

For both analyses (enforced displacement or force) the reinforcement threshold is independent on the maximum applied load. This threshold corresponds to a displacement ratio equal to 0.15 (Charrier et al. 2002), and to a zero force ratio (cf. Fig. 4). Consequently, a negative load ratio crack propagation test $\left(\mathrm{L}_{\min }<0\right.$ and / or $\left.\mathrm{F}_{\min }<0\right)$ never induces reinforcement : crack growth curves for such conditions are similar to those obtained under relaxing conditions.

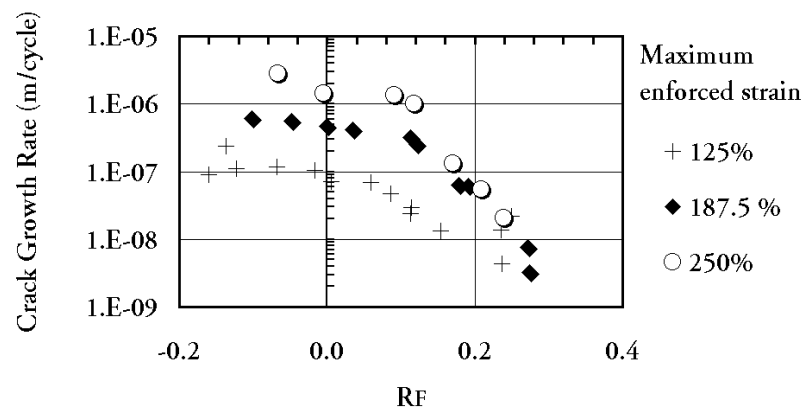

Figure 4 : Crack propagation - characterization of the reinforcement for several force ratio and several maximum applied loads.

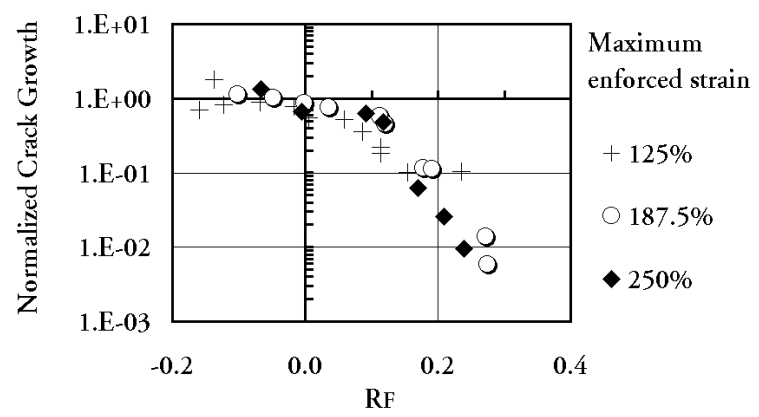

Figure 5 : Crack propagation reinforcement law.

The function $f(R)$ is determined using a master curve that represents the normalized crack growth rate versus the load ratio. For each experimental condition, the normalized crack growth rate is defined as the ratio between the measured crack growth rate and the crack growth rate measured with the same maximum load under relaxing conditions. The master curve based on displacement ratio is given by Charrier et al. (2002) and the master curve based on force ratio, named crack propagation reinforcement law, is presented on Figure 5 and can be fitted by the following equation:

$f\left(R_{F}\right)=1$ if $R_{F} \leqslant 0$

$f\left(R_{F}\right)=10^{-\left(a R_{F}^{2}+b R_{F}\right)}$ if $R_{F}>0$

\subsection{Crack initiation test}

Crack initiation tests are performed using two specific axi-symetrical test specimens named Diabolo and AE2 (cf. Fig. 6). Methodology used to determine the duration life is detailed by OstojaKuczynski et al. (2003).
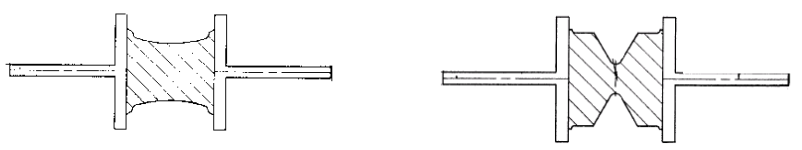

Figure 6 : Crack initiation test specimen.

The methodology applied to characterize the reinforcement phenomenon for crack initiation tests is quite similar to the one defined previously (see crack propagation tests). A maximum applied load is fixed and several minimum load conditions are tested in order to study a large range of load ratios. Three to five test specimens are tested for each condition.

Influence of compression level on duration life is highlighted using Diabolo test specimens. Corresponding tests are performed under enforced displacement conditions. The maximum applied load corresponds to a local maximum strain equal to $100 \%$ in the mid plane of the test specimen. The minimum applied load varies between $0 \mathrm{~mm}$ (relaxing condition) and - $15 \mathrm{~mm}$ (test specimen buckling). Results of this test campaign are presented on Figure 7. For a test specimen under a negative load ratio solicitation, the duration life does not depend on the compression level. In that case, only the maximum applied load drives the duration life and no reinforcement is observed.

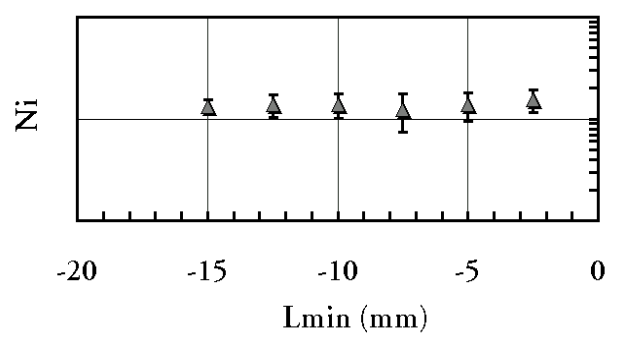

Figure 7 : Influence of compression level during traction compression tests

The influence of a positive load is investigated specifically with AE2 test specimens. In order to 
highlight the influence of the load ratio on the reinforcement threshold, two complementary test campaigns (imposed displacement and imposed force) were performed. Maximal imposed displacement and force were chosen to lead to the same duration life under relaxing conditions.

Results of the test campaign under imposed displacement conditions are presented on Figure 8. Theses results are in accordance with all published works about filled natural rubber fatigue characterization: when the minimum displacement is greater than a given threshold, the duration life increases significantly. This displacement threshold ratio is equal to 0.2 for the tested compound. Similar results were obtained previously (Cadwell et al. 1940).

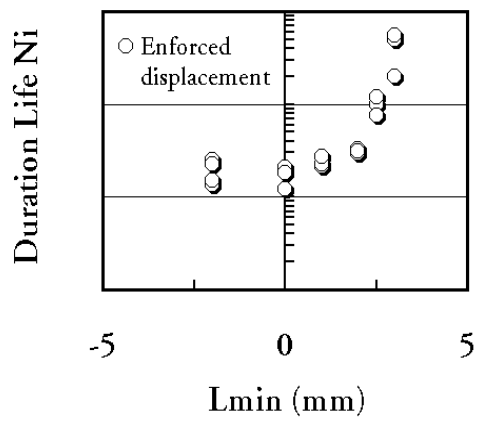

Figure 8 : Reinforcing threshold for crack initiation tests under enforced displacement.

Results of the test campaign using enforced force conditions are presentend on Figure 9. The curve evolution is very similar to the one obtained with enforced displacement conditions. However, in that case, the load threshold ratio is zero.

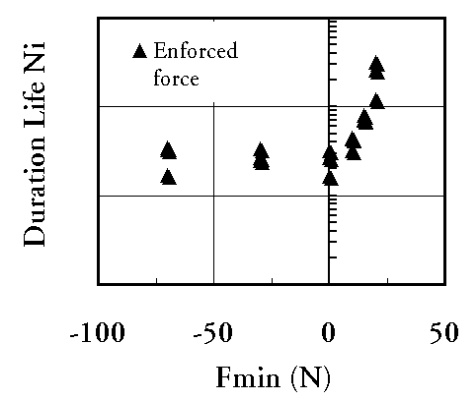

Figure 9 : Reinforcing threshold for crack initiation tests under enforced force.

In a similar way as for the crack propagation approach, it is possible to exhibit a master curve to quantify the influence of the load ratio by maintaining the maximum load. This master curve represents the normalized duration life (defined by the ratio between duration life under non relaxing and relaxing conditions) versus the load ratio.

In order to construct this master curve, complementary tests are performed with different maximum loads and the corresponding results are reported in Figure 10.

This master curve defines the crack initiation reinforcement law. Moreover, the existence of this master curve shows that the reinforcement initiation law does not depend on the maximum applied load but only on the load ratio.

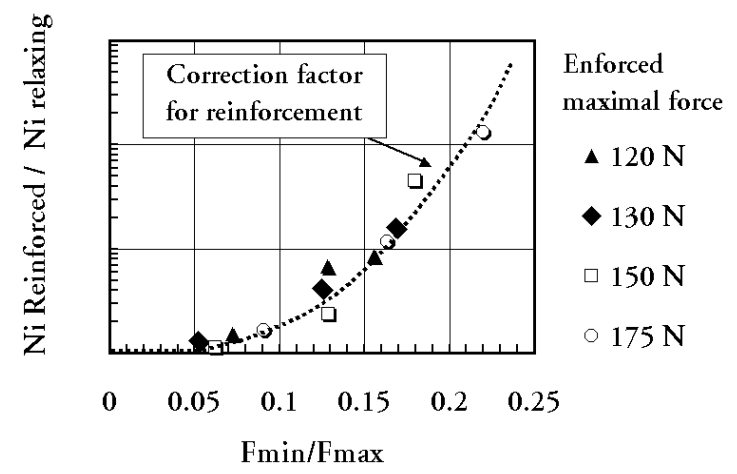

Figure 10 : Crack initiation reinforcement law.

\section{REINFORCEMENT LAW DISCUSSION}

\subsection{From crack propagation curves to crack initiation curves}

Crack initiation tests can be analyzed assuming a stochastic distribution of internal pre-existing flaws in the rubber matrix, characterized by the mean value size classically labeled $\mathrm{c}_{0}$. Then, crack initiation corresponds to the propagation of a $c_{0}$ initial size crack until it reaches a size of $c_{i}$, the size of the macroscopic crack defining the end of life. Using this assumption, it is possible to calculate the crack initiation curve from the crack propagation equation (3).

The number of cycles until the crack initiation $\mathrm{N}_{\mathrm{i}}$ is then calculated using the following equation:

$$
N_{i}=\int_{0}^{N_{i}} d N=\int_{\alpha_{0}}^{c_{i}} f(R)^{-1} \cdot B_{0}^{-1} \cdot \Delta T^{-\beta_{0}} \cdot d c
$$

The main problem is the determination of the tearing energy for the test specimen that includes a small crack. In the present study, comparison between results obtained with crack propagation tests and crack initiation tests is performed on Diabolo test samples. According to Mars (2000), in that case (uniaxial tensile test), the available tearing energy for small crack in front of the test specimen cross section can be calculate using the following equation:

$\Delta T=2 \cdot k \cdot c \cdot \Delta W$

where $\mathrm{c}$ is the crack length, $\Delta \mathrm{W}$ is the cyclic strain energy density, and $\mathrm{k}$ is a parameter that depends on the maximum strain applied during a cycle. A second assumption is needed to evaluate equation (6). For the parameter $\mathrm{k}$ we propose to use the function evaluated by Lake (1970) for small cracks ondumbbell test specimens: 
$k=\frac{\pi}{\sqrt{\lambda}}$

where $\lambda$ is the maximal stretch applied locally during the cycle.

Under relaxing conditions $(\mathrm{R}=0)$, the reinforcement law is equal to 1 and the cyclic strain energy density $\Delta \mathrm{W}$ is equal to the maximum strain energy density during the cycle $\mathrm{W}_{\max }$. This parameter has been evaluated using FEM. Then, crack initiation curve for relaxing conditions is calculated by intergation of equation (5) and leads to the following equation:

$N_{i}=\frac{W_{\max }^{-\beta_{0}}}{\left(\beta_{0}-1\right) \cdot B_{0} \cdot[2 \cdot k]^{\beta_{0}}} \cdot\left[c_{0}^{-\left(\beta_{0}-1\right)}-c_{i}^{-\left(\beta_{0}-1\right)}\right]$

Two parameters in equation (8) have not been determined: pre-existing and final crack size. Experimental procedure used to define the end of life specifies a critical flaw size of $2 \mathrm{~mm}$ (OstojaKuczynski et al. 2003). Intrinsic pre-existing flaw size is determined to correlate Wöhler curve measured on crack initiation tests to the Wöhler curve calculated with crack propagation law (cf. Fig. 11). The initial flaw size that optimizes the correlation level is equal to $70 \mu \mathrm{m}$. This value is in accordance with other results founded in bibliographic review.

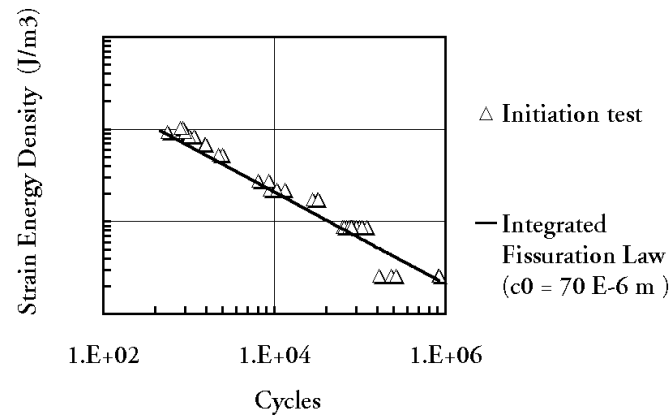

Figure 11 : Crack initiation test results and integrated crack propagation law under relaxing conditions.

Under non relaxing conditions, the reinforcement law $f(R)$ is given by (4). Note that the strain energy density $\Delta \mathrm{W}$ is equal in this case to $\mathrm{W}_{\max }-\mathrm{W}_{\min }$. Using this law, it is possible to suggest similar prediction of duration life $\left(\mathrm{N}_{\mathrm{i}}\right)$ based on the crack propagation law, but under non relaxing conditions. The new version of the crack initiation law based on non relaxing propagation law is then:

$$
N_{i}=\frac{\left[W_{\max }-W_{\min }\right]^{-\beta_{0}}}{\left(\beta_{0}-1\right) \cdot f(R) \cdot B_{0} \cdot[2 \cdot k]^{\beta_{0}}} \cdot\left[c_{0}^{-\left(\beta_{0}-1\right)}-c_{i}^{-\left(\beta_{0}-1\right)}\right](9)
$$

The Haigh diagram (duration life versus $\mathrm{F}_{\text {mean }}$ and $\Delta \mathrm{F}$ ) presented in Figure 12 proposes a superposition of the duration life $\mathrm{N}_{\mathrm{i}}$ measured directly on Diabolo test specimen and the duration life predicted by (9). Each experimental point of this diagram represents the mean-value of $\mathrm{N}_{\mathrm{i}}$ based on three to five test re- sults obtained on Diabolo test specimen. Isoduration life curves are calculated using the crack propagation law assuming an initial flaw size $\mathrm{c}_{0}$ equal to $70 \mu \mathrm{m}$. Because equation (9) is based on strain energy density and iso-duration life curves are plotted in a force diagram, FEM is used to estimate the relationship between forces and strain energy density. Correlation between experimental results obtained on Diabolo and prediction based on crack propagation law is excellent.

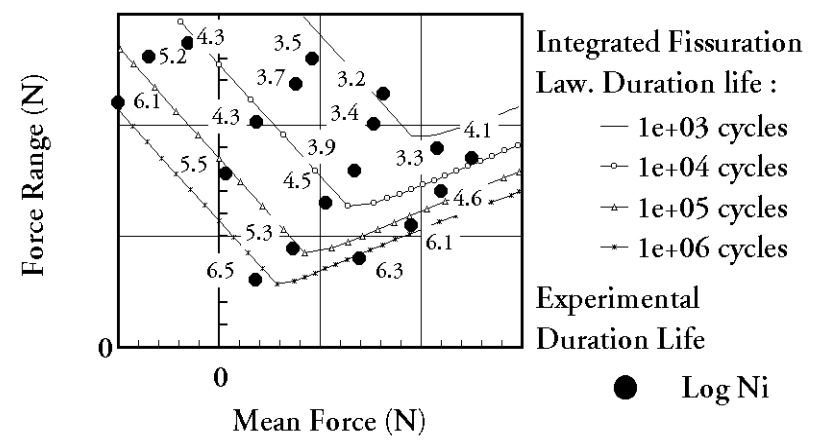

Figure 12 : Haigh diagram obtained by fissuration law integration. Comparison with initiation experimental results.

\subsection{Application to Road Load Data analysis}

The Road Load Data signal plotted on Figure 1 is chosen to validate the validity of the mean stress correction law obtained during this study. Five tests are performed on the AE2 test specimen in order to take into account durability scattering effect. Mean duration life (i.e. number of signal repetitions) is equal to 5 500. Rainflow counting method is used to analyze this signal and transform it into a series of basic cycles (Steinwegger \& Flamm, 2003).

Three different Rainflow matrix post-treatment methods are compared. With the first one, reinforcement is neglected: the duration life is determined only with the maximum value of each basic cycle. The number of signal repetitions predicted until failure component is in this case equal to 2400 . This value is lower than the measured one, because the small cycles with important value of $F_{\max }$, that do not involve damage, are taken into account. With the second approach, all the tensile-tensile cycles are ignored. This methodology assumes that these cycles not participate to the damage because of reinforcement phenomenon. In that case, the duration life is higher than the measured one and is equal to 10000 repetitions. As a consequence, we can say that some of the tensile-tensile cycles involve non-negligible damage. The last method uses the reinforcement law (cf. Fig 10.). With this approach, tensile-tensile cycle damage is well estimated and the predicted duration life (6 300 cycles) is close to the measured one. 


\section{CONCLUSION}

The experimental database constructed during this work enables to quantify the reinforcement phenomenon and to characterize the associated threshold. Thus, it is exhibited that, whatever may be the control parameter of the test (force or displacement), reinforcement appears as soon as the stress remains positive during all the cycle. Moreover, reinforcement can be described by a unique master curve independent of the maximal applied load.

The database enables also to compare crack initiation and crack propagation phenomena. The comparison of crack initiation results and extrapolation of crack propagation law to crack initiation, whatever the kind of loading (tensile-compression, relaxing, tensile-tensile), is satisfactory. It suggests a distribution of pre-existing flaws with a mean size of $70 \mu \mathrm{m}$. The reliability of the correlation points out that, for filled natural rubber, crack propagation is the physical phenomenon that drives crack initiation (for relaxing and non-relaxing conditions).

Finally, identified mean stress correction is applied to analyze Road Load Data signals. Again, predictions are sufficient.

\section{REFERENCES}

André, N., Cailletaud, G. \& Piques, R. 1999. Haigh Diagram for Fatigue Crack Initiation Prediction of Natural Rubber Components. Kautschuk Gummi Kunstoffe : 52, 120-123.

Cadwell, S. M, Merril, R.A, Sloman, C.M \& Yost, F.L. 1940. Dynamic Fatigue Life of Rubber. Industrial and Engineering Chemistry, 12, $n^{\circ} 1: 19-23$.

Charrier, P., Royer, J. \& Esbelin, P. 1998. Glass Flexible gluing on passengers vessels - Durability. Proceedings $4^{\text {th }}$ European Conference on Adhesion, Garmish - Partenkirchen, 6-11 September 1998.

Charrier, P., Ostoja-Kuczynski, E., Verron, E. Gornet, L \& Chagnon, G. 2002. Influence of loading conditions on fatigue properties for filled elastomers. Proceedings International Rubber Conference, Praha, 1-4 july 2002.

Le Cam, J. B., Huneau, B., Verron, E. \& Gornet, L. 2004. Mechanism of Fatigue Crack Growth in Carbon Black Filled Natural Rubber. Macromolecules : 37 (13), 50115017

LeGorju-Jago, K. \& Bathias, C. 2002. Fatigue Initiation and Propagation in Natural and Synthetic Rubbers. International Journal of Fatigue : 24, 85-92

Lindley, P. B. 1974. Non Relaxing Crack Growth and Fatigue in a Non Crystallising Rubber. Rubber Chemistry and Technology : 47, 1253-1264.

Mars, W. V. 2001. Multiaxial fatigue of rubber. Ph-D Dissertation, University of Toledo.

Ostoja-Kuczynski, E., Charrier, P., Verron, E., Marckmann, G., Gornet, L. \& Chagnon, G. 2003. Crack initiation in filled natural rubber : experimental database and macroscopic observations. Proceedings Third European Conference on Constitutive Models for Rubber, London, september 2003.

Piques, R. \& Saintier, N. 2001. Critère multiaxial de prévision des durées de vie en fatigue de composants élastomères NR chargés en noir de carbone. Revue des composites et des matériaux avancés: 11, 97-110.

Rivlin, R. S. \& Thomas, A. G. 1953. Rupture of rubber. I. Characteristic energy for tearing. J. Polym. Sci. 10 : 291318.

Saintier, N. 2001. Prévision de la Durée de Vie en fatigue du caoutchouc naturel sous chargement multiaxial. Ph-D Dissertation, Ecole des Mines de Paris.

Steiwegger, T., Flamm, M. \& Wetin, U. A Methodology for test time reduction in Rubber part testing. Proceedings Third European Conference on Constitutive Models for Rubber, London, september 2003

Thomas, A. G. 1958. Rupture of Rubber. V. Cut Growth in Natural Rubber Vulcanizates. . J. Polym. Sci. 31 : 467-480. 